\title{
AÇÕES COLETIVAS, NOVAS FORMAS DE ARTICULAÇÃO POLÍTICA-OLIGÁRQUICA E O DECLÍNIO DAS ESQUERDAS LATINO-AMERICANAS ${ }^{1}$
}

Collective actions, new forms of oligarchic political articulation and the decline of the latin american left-wing

\author{
CHÁVARRO BERMEO, Dana Milena² \\ PINHEIRO, Wellington Duarte ${ }^{3}$
}

\begin{abstract}
Resumo: Fundamentado no debate sobre o emergente desafio enfrentado pelas ações coletivas latino-americanas no contexto do novo pacto político entre a oligarquia políticoconservadora e o capitalismo especulativo extrativista (Bringel \& Pleyers, 2017) este artigo observou que as mobilizações coletivas ressignificaram seus repertórios a fim de reivindicar o fortalecimento do ideal republicano capaz de reativar a conquista de bens comuns como a cidadania e a solidariedade contemporânea. Demonstramos que o surgimento de política utilitarista como o neodesenvolvimentismo e neoextrativismo latino-americano implicou a destituição do ideal republicano e a queda dos regimes de esquerda. Isto provocou o surgimento de ações coletivas preocupada em transformar o mal-estar moral provocado pela implementação de política mercantil. Norteado pela discussão antiutilitarista do novo pacto político republicano na região e pelo debate decolonial sobre a queda de governos progressistas apresentamos uma compreensão preliminar das novas possibilidades de ativismo político.
\end{abstract}

Palavras-chaves: Ações coletivas. Oligarquias. Declínio das esquerdas.

Abstract: In the new debate about the current challenges faced by the collective Latin American actions in the new sociological context, of arrangement between conservative oligarchy and extractive speculative (Bringel \& Pleyers, 2017). It is feasible that the movements gave new meanings to the repertories, with the goal of enhance the republican ideals, ideals that are capable of reactive the conquest of common goals, such as the idea of citizenship and modern solidarity. With this emergency of neo-developmentalism utilitarian policy (neo-development and Latin American neo-extractivism) it is generate the fall of republican ideals and the ending of left governments, this also generate, the emergency of collective action that take care the moral malaise. Using the anti-utilitarian contributions of the new political arrangements in the region, and the decolonial debate on the fall of left regimen, this documents shows a preconception of the new possibilities of the political activism.

Keywords: Collective actions. Oligarchies. Decline of left regimes.

\footnotetext{
${ }^{1}$ Recebido em: 31 Ago. 2018. Aprovado em: 01 Out. 2018.

${ }^{2}$ Doutoranda do Programa de Pós- Graduação em Sociologia da Universidade Federal de Pernambuco PPGS-UFPE. Bolsista do Programa Estudantes-Convênio de Pós-Graduação - PEC-PG, da CAPES/CNPq Brasil.danachabe@yahoo.com

${ }^{3}$ Doutor em Educação da UFPE. Professor da Faculdade Osman da Costa Lins - FACOL. pinheiraosociais@yahoo.com.br
} 


\section{Introdução}

A América Latina na década dos anos 2010 vivenciou a queda de regimes democráticos alinhados à filosofia de governos progressistas que desde o início deste século conduziram políticas de diminuição da desigualdade social na Região. Ações de combate à fome e a pobreza constituíram bandeiras destes governos de esquerda e foram utilizadas como modelo de ação pública em escala mundial (Gudynas, 2016; Martins, 2017).

A partir desta nova conjuntura caracterizada, por um lado, pela desnacionalização do sistema econômico e pela oligarquização do sistema político de cada país. Por outro lado, tal configuração favoreceu o ressurgimento da política econômica neodesenvolvimentista que foi repaginada por uma nova classe dirigente burocrática que mais tarde tornou-se representante do capital internacional na região. Além disto há que se reconhecer o fortalecimento do neoliberalismo como tradição político-econômica que conduziu a adequação funcional da máquina pública em prol do mercado e do capital internacional (Alves, 2013).

Na prática isto implicou a tríade composta pela desregulação, privatização e retraimento do estado da ordem econômica. Neste contexto emergiu uma nova configuração na qual o estado assumiu características do mercado como a mínima intervenção social e a fragilização o chamado estado de bem-estar social (Martins, 2017; Caillé, 2013; Cusset, 2017).

Esta readequação do "espírito do capitalismo" caracterizou também o esvaziamento da ética social no mundo do trabalho e provocou um mal-estar moral e emocional tanto na comunidade política quanto nos movimentos sociais. Na esteira disto as mobilizações além de identificarem a contradição na relação capital-trabalho também refletiram sobre a perda de direitos e a expropriação dos indivíduos no processo de fragmentação dos bens comuns.

Em termos da sociologia política, a fragilização dos bens comuns foi uma das consequências do declínio democrático dos regimes de esquerda e do esfacelamento republicanista dos bens comuns que apesar das contradições deste último, certamente, 
constituiu uma referência institucional e jurídica relevante para organizar as lutas sociais e assegurar conquistas de direitos de cidadania sob proteção do estado (Martins, idem).

Inerente ao novo panorama das lutas sociais emergiram algumas ações coletivas com o objetivo de manter as conquistas cidadãs amparadas pelos ideais republicanos previstos nas cartas constitucionais. Os ativistas também reuniram esforços comuns numa tentativa de reação à degradação da ação estatal e da proteção social.

Em outras palavras, estas mobilizações estavam reivindicando a manutenção das conquistas sociais, políticas e jurídicas, ao mesmo tempo, expressam um sentimento de denúncia contra a postura do estado mínimo que precariza e retira a conquista de direitos adquiridos. Neste contexto aludimos à "caixa de pandora" que foi aberta pelas manifestações de junho de 2013 no Brasil e pelas manifestações em defesa do processo de paz na Colômbia em 2012.

Nesta conjuntura cada movimento reagiu segundo as particularidades políticas do país. Expliquemos melhor: no caso colombiano as mobilizações pela paz pretenderam resolver o problema social do conflito armado que o estado ${ }^{4}$ há mais cinco décadas não conseguiu articular uma solução desta questão. Na esteira disso as ações coletivas provocaram pressão política para que o governo dialogasse com as guerrilhas das Forças Armadas Revolucionária da Colômbia (FARC) e com o Exército Nacional de Libertação (ELN).

Com efeito, por um lado, o caso colombiano demonstrou o ressurgimento da mobilização cidadã e dos movimentos sociais que reivindicaram a construção de um novo acordo de paz a fim de iniciar uma mudança radical no sistema democrático daquele país.

Por outro lado, no caso brasileiro, as manifestações de junho de 2013 ocorreram no auge de expansão de políticas neoliberais adaptadas à lógica político-produtiva do neodesenvolvimentismo. Na esteira disto há que se reconhecer que as manifestações do Brasil atraíram diversos tipos movimentos sociais desde os tradicionais até novíssimos

\footnotetext{
${ }^{4}$ É interessante ressaltar que na democracia da Colômbia até a primeira metade do século XX a figura do Estado como provedor da ordem social é praticamente inexistente (Lozano Guillén, 2014) fato que proporcionou o surgimento das organizações de grupos armados à margem da lei (guerrilhas, paramilitares, narcotráficos e etc).
} 
movimentos com ações voltados para objetivos difusos e sem bases ideológicas claras, mas em geral voltados para reivindicar políticas públicas igualitárias (Gohn, 2017).

Deslocando a questão para o campo da sociologia antiutilitarista há que se compreender que o caso brasileiro promoveu espaço para o ressurgimento de novas lutas populares de vanguarda que têm como uma das suas metas a desmercantilização do transporte coletivo. Isto está expresso na questão da tarifa zero que se refere à luta pela permanência da proteção social do estado e a afirmação cidadã republicana na garantia de direitos para todos (Alves, 2013, Gohn, 2017, Sader, 2017).

Para a especificidade deste artigo analisamos as ações coletivas latino-americanas a partir de dois casos específicos. Um: o Movimento Marcha Patriótica (MARCHA) que faz parte dos movimentos sociais que atuaram na Colômbia a partir de uma ampla base de atores sociais preocupados em implementar um projeto de cidadania e de organização da nação, tendo como eixo articulador a solução negociada do conflito armado. Dois: $o$ Movimento Passe Livre (MPL) que fez parte das mobilizações sociais que germinaram no Brasil durante o início dos anos 2000 e foi um dos protagonistas das jornadas de junho em 2013.

Após a apresentação panorâmica das duas ações coletivas mobilizadas nesta investigação é importante compreender as tramas sociológicas desenvolvidas nas estruturas da sociedade latino-americana que oportunizou a queda dos regimes de esquerda em plena conjuntura de ressurgimento do neoliberalismo.

\section{Sobre o Ressurgimento do Neoliberalismo na América Latina}

Os tempos sombrios ${ }^{5}$ que assola o cenário político-social na América Latina apontam para a perda de garantia social fundamentada pelo republicanismo conservador, mas que vinha respondendo positivamente às pressões dos movimentos democráticos nos últimos tempos.

Nas palavras de A. Honneth em O Direito da Liberdade (2015) observa-se que é preciso repensar o modelo de teoria da justiça atrelado ao princípio formal e a fixação de

${ }^{5}$ Cf. Arendt (2008). 
norma regulatória. Para P. H. Martins $(2016)^{6}$ a ameaça aos fundamentos do republicanismo é observada no processo de ausência de reconhecimento de direito nas legislações latino-americanas, sobretudo, pelo fato de tais garantias sociais se equilibrarem numa equação instável entre o privado e o público, sendo este último submetido ao primeiro, sempre que a equação ameaça se desfazer.

Tendo em vista a conjuntura contemporânea do sul global observamos que o esfacelamento do republicanismo está correlacionado às transformações dos governos progressistas que foram depostos por trama política articulada entre o poder legislativo e o judiciário ${ }^{7}$ e devido à pressão do capital financeiro não tiveram como manter a governabilidade nacional.

Por conseguinte, os governos neoliberais na região promoveram alterações constitucionais que estão desmontando a proteção social, pois as práticas de "austeridade" resultaram no colapso de políticas sociais como os direitos à educação de qualidade, à saúde, à garantia previdenciária entre outras. Incorporando uma análise crítica de tal configuração observa-se que esta série de transformação políticoeconômico-social representa o que muitos sociólogos denominam do "ressurgimento" do projeto neoliberal de sociedade, o qual parecia estar ausente do cenário político.

A partir uma análise profunda é possível observar que esse modelo de gestão capitalista internacional expandiu-se "silenciosamente" e se fortaleceu com as contradições dos governos progressistas dos países latino-americanos entre os anos 2000 e 2016, uma vez que o processo de submissão da comunidade política latino-americana ao capitalismo financeiro internacional reiterou uma metáfora equivocada que remete à ideia da mão invisível smithiana.

$\mathrm{Na}$ prática o que vimos não foi o funcionamento do mercado guiado espontaneamente por leis "invisíveis" de mercado; ao contrário disto, houve a retomada de poder político e o fortalecimento de oligopólios financeiros que remontam ao autoritarismo político-econômico das três últimas décadas do século XX.

$\mathrm{Na}$ contracorrente disto emergiram movimentos sociais mobilizando ações coletivas que, por um lado, reivindicam uma nova organização moral e política preocupada em garantir conquistas cidadã prevista pelo modelo do republicanismo. Por

\footnotetext{
${ }^{6}$ Cf. Martins (2016).
}

${ }^{7}$ Cf. Alves et al (2017). 
outro lado, tais movimentos denunciaram a materialização do projeto de empobrecimento da vida social caracterizado pela fragilização das políticas dos bens comuns.

A perda de direitos sociais e o esvaziamento do estado de bem-estar social ratificam mal-estar social e moral da pós-modernidade salientado por alguns teóricos (Bauman, 1998; Dardot \& Laval, 2016; Sousa Santos, 2016; Martins, 2016, 2017).

\subsection{Política do Neodesenvolvimentismo.}

O neodesenvolvimentismo foi uma prática político-econômica genuinamente brasileira fundamentada num paradoxo onde governos pós-neoliberais comprometem-se com crescimento econômico e redistribuição de renda, porém, de maneira simultânea, preservaram os pilares da política neoliberal onde o estado, por um lado, passou a incentivar a circulação de capital ao financiar empreendimentos privados e, por outro, diminui sua capacidade intervenção social na implementação de políticas públicas capazes de promover a circulação bens sociais comuns da nação (Alves, 2013; Martins, 2017).

Em termos da geografia social observamos que os países que representam o corredor atlântico como Argentina, Brasil e Uruguai, "amorteceram" as consequências da crise econômico-estrutural e o conflito social gerado pelo projeto egoísta neoliberal inscrito na perspectiva da política neodesenvolvimentista. Em linhas gerais, houve um pseudo investimento em política voltada para manter o poder de consumos dos setores assalariados o que permitiu postergar a crise sistêmica até o ano de 2016.

Aprofundando esta questão as nações progressistas tiveram que postergar o colapso social e criaram programas de transferência de renda que amenizou a precariedade do "sucateamento" das políticas de bens comuns (trabalho, saúde e educação pública), porém a intervenção estatal na economia nacional com vista a neutralizar a pressão interna não foi suficiente para conter a crise progressiva que fragilizou a ação estatal com consequente colapso das políticas públicas. Este 
esgotamento do neodesenvolvimentismo está devidamente analisado por autores como Sader (2017), Alves (2013) e Mattei, (2013).

Para autores como A. Boito Jr. \& T. Berringer (2013) o neodesenvolvimentismo representa uma das faces do projeto neoliberal de sociedade. Eles destacam algumas características, a saber: otimização do crescimento econômico estatal, diminuição de intervenção estatal no mercado, transnacionalização do capital; maior investimento em políticas industriais, investimento em tecnologia da informação e maior concentração de capital ativo para o ramo empresarial.

É relevante ressaltar que o projeto apresentado pelo neodesenvolvimentismo está associado à política econômica da segunda metade dos anos 2000 o que coincidiu com a chegada ao poder do governo Lula e a implementação do seu governo progressista.

Para avançar na compreensão desta política econômica dois aspectos merecem destaques. Um: o neodesenvolvimentismo pode ser compreendido como uma "espécie" de terceira via ${ }^{8}$ e foi interpretado como em resposta ao imperativo do capital especulativo-financeiro. Dois: a política econômica do neodesenvolvimento favoreceu o projeto político de centro-esquerda que tanto combatia os excessos dos "revolucionários de esquerda" quanto se afastava do segmento mais conservador do sistema político brasileiro. Sobre esta configuração político-econômica é relevante reconhecer que:

Em linhas gerais, pode-se dizer que o "Novo Desenvolvimentismo" até aqui discutido pretende ser a construção de um "terceiro discurso" entre a ortodoxia neoliberal e o populismo, com o objetivo de implementar um conjunto de reformas das políticas macroeconômicas e das instituições, visando fortalecer tanto o estado como o mercado e, com isso, tornar o país mais competitivo no cenário internacional (Mattei, 2013, p. 49).

Ainda versando sobre o fortalecimento do estado na prática política é importante perceber que a estratégia de ampliação da máquina pública, o fortalecimento administrativo e a realocação de recursos públicos para empresas nacionais protagonizou a inserção do Brasil no comércio internacional. Isto conferiu "status" e "prestígio" ao

\footnotetext{
8 Termo cunhado pelo sociólogo Anthony Giddens. Para esse pensador a proposta da terceira via defende que as instâncias do governo, da economia e da sociedade civil deveriam estar conectadas pelos interesses de solidariedade e justiça social o que promoveria equilíbrio de interesse entre a sociedade e o mercado. Logo seria possível pensar num estado promotor deste equilíbrio social. 0 que, de certa forma, ocorreu com as políticas de distribuição de renda (C.f. Giddens, 2001).
} 
neodesenvolvimentismo do capitalismo cibernético ${ }^{9}$ brasileiro (Alves, 2013; Martins, 2017; Mattei, 2013).

No projeto político instaurado pelo neodesenvolvimentismo há que se compreender o fundamento ideológico nacionalista que remonta ao antigo manual desenvolvimentista de fortalecimento da burguesia interna como força dirigente dos conglomerados industriais, pois se especulava que o poderio econômico fosse ampliado com o investimento de capital estrangeiro.

Ainda versando sobre esse projeto econômico percebeu-se que apesar da heterogeneidade havia ampla base social representada por grupos sindicais, baixa classe média e trabalhadores agrícolas que eram alvos de programas sociais como Minha Casa, Minha Vida e Bolsa Família ${ }^{10}$. Com efeito, estes diferentes setores da sociedade brasileira eram a base do projeto político neodesenvolvimentista (Alves, 2013).

Nesta conjuntura a classe política oligárquica controlava o jogo de interesses envolvendo os atores empresariais e percebeu que uma das novidades no equilíbrio da balança de poder foi a construção de um pacto entre a oligarquia nacional e empresas transnacionais.

Para Neste W. G. Santos (2017) e Martins (2017) reconhecem que apesar do ganho aparente com políticas de redistribuição de renda para a classe trabalhadora o que houve de fato foi o planejamento da fragmentação do poder estatal como provedor de bens comuns de cidadania para forjar uma nova articulação no jogo de poder no qual a oligarquia político-burocrática conseguiu, tradicionalmente, mante-se no poder políticoadministrativo da nação.

A sociedade civil tinha participação heterogênea e diversificada do ponto de vista ideológico, mas eram evidentes os esforços dos movimentos sindicais e da militância do Partido dos Trabalhadores (PT) para canalizar as insatisfações em apoio ao neodesenvolvimentismo. A política de transferência de renda oferecida pelos petistas

\footnotetext{
9 Termo proposto por P. H. Martins em: Republicanismo solidário e missão da universidade pública (2017). Para esse pesquisador o capitalismo cibernético pode ser entendido como uma transformação ampliada das táticas de exploração já usadas pelo capital especulativo nas nações periféricas, pois nesta modalidade "virtual" da especulação. Há novas maneiras de pressionar as nações e fragmentar os bens comuns republicanos.

10 Para além do caráter economicista do neodesenvolvimentismo é prudente reconhecer a função social que estes programas desempenharam, sobretudo, porque conseguiram atingir pessoas de baixo estrato social (Sader, 2016, W. Santos, 2017).
} 
durante os anos de 2003 a 2016 constitui prova desta estratégia (Boito Jr \& Berringer, 2013).

Entretanto, a ilusão da burguesia nacional empreendedora e simpatizante do modelo neodesenvolvimentista se desfez, uma vez que já estava muito comprometida com o capital financeiro e especulativo internacional e agiu de forma ambígua com relação aos governos petistas procurando maximizar os ganhos com empréstimos de bancos públicos.

O processo de financeirização do empresariado industrial brasileiro já estava bem avançado e as tentativas do governo Dilma de controlar o sistema bancário foi a senha para o golpe que se armou contra seu governo. Atrelado a isto houve a incapacidade dos atores neodesenvolvimentistas entenderem que o endividamento do estado com subsídios ao setor privado tinha limite prático e isto contribuiu para a paralisia política e econômica que desarticulou o fundamento teórico e prático do neodesenvolvimentismo.

Na esteira desses acontecimentos observou-se a degradação das contas estatais, aprofundamento da crise fiscal o que contribuiu para deteriorar as políticas públicas e culminou com "as demandas sociais postas pelos protestos de rua que não poderiam ser atendidas por um governo neodesenvolvimentista retraído pelas atuais contradições político-moral-econômica daquele momento" (Alves, 2014, p.5).

A partir deste contexto caracterizado pela incapacidade estatal de suprir as demandas e reivindicações dos movimentos sociais emergiu uma série de "revelação" seletiva sobre escândalos morais e esquemas de corrupção de diversos agentes públicos que abalaram a democracia brasileira. Tais acontecimentos proporcionam um terreno fértil para o surgimento do que ficou conhecido como as Jornadas de Junho de 2013.

Guardando as devidas proporções esse fenômeno de reengenharia sócio-político de racionalização das ações econômicas e da fragilização dos bens comuns de cidadania ocorreu também na Colômbia. Diferente do caso brasileiro o aprofundamento do espírito neoliberal ocorreu com o fortalecimento da política neoextrativista. Posicionando-se contra esta política mercantil os atores sociais coletivos desencadearam com maior ênfase a reivindicação de direito republicano contextualizado no processo dos acordos de paz. 


\subsection{Sobre as políticas do Neoextrativismo na América Latina.}

Semelhante ao neodesenvolvimentismo brasileiro o neoextrativismo constituiu uma política de reconfiguração do neoliberalismo na América Latina de tradição espanhola. Sua origem também advém de acordo entre oligarquia político-administrativa local e o capital especulativo internacional promovendo um tipo de acumulação financeira nacionalista e estadista que a partir da redistribuição maciça de recursos tributários conseguiu temporariamente amenizar o quadro de pobreza na região.

A estrutura de funcionamento do neoextrativismo reside no que autores como E. Gudynas (2016 et al) em: Rescatar la esperanza. Más allá del neoliberalismo y el progressismo denominou de prática política dos governos progressistas e teve protagonismo na região no período de 2000 até meados dos anos 2013. De certo modo estas gestões se caracterizaram pela exploração intensiva dos recursos naturais o que fragilizou a proteção dos recursos ecológicos.

Segundo este pesquisador, o neoextrativismo é uma modalidade de desenvolvimento flexível na exploração de recursos naturais. No entanto, rígido na capacidade de acumular recursos advindos dessas atividades. Desta forma, atividades de mineração, extração petrolífera e a exploração do agronegócio constituem exemplos desta prática especulativa (Gudynas et al, 2016).

Segundo Martins (2017), o neoextrativismo observado numa perspectiva sistemática pode ser interpretado como uma forma de reprodução do sistema mercantilista internacional, pois ao desorganizar as fronteiras políticas dos estados nacionais, ameaçar a soberania e a governabilidade dos regimes republicanos preocupados em garantir os bens comuns da nação abriu-se uma janela de oportunidade para a exploração da capital especulativo.

A contaminação das águas, o empobrecimento da terra e destruição de área verde, a expulsão da comunidade indígena, quilombolas e ribeirinha constituem exemplos de como o pacto republicano conservador agravou o quadro de exclusão social na América Latina (Martins, 2017; Santos, 2017).

A partir dessa caracterização do neoextrativismo é relevante compreender como essa prática política desmontou o aparato de segurança republicana estatal ao liberar os 
fluxos de troca mercantil, desorganizou o sistema de transferência de renda e fragilizou os laços de articulação política entre o estado e os atores coletivos.

\subsection{Sobre as Políticas Progressistas Latino-Americanas.}

Para E. Gudynas (2016), M. Svampa (2016) e B. Sousa Santos (2016) é importante observar que uma das possibilidades de entendimento da transformação oriunda do pacto político-econômico latino-americano advém do neoextrativismo, uma vez que, segundo esses estudiosos, o neoextrativismo é uma reconstituição ampliada das antigas práticas de extrativismo que foi reativada nos governos progressistas.

Ao identificarmos o neoextrativismo como uma das modalidades de prática política orientada pela aliança oligárquica que coordenou a intervenção estatal na região é fundamental entender como esta "antiga prática política" manteve-se no poder. Dentre outras possibilidades de análise observamos que o pacto político entre a oligarquia burocrática e o capital especulativo manteve a mesma base de atuação fundamentada na expansão do consumo e no crescimento econômico oriundo das exportações de produtos minerais (Gudynas et al, 2016).

$\mathrm{Na}$ Argentina, por exemplo, a política neoextrativista fundamentou o governo progressista conhecido pela postura nacional-popular. No caso do Equador e na Venezuela tal prática política foi a base para o que se denominou de socialismo do século XXI. No caso boliviano as estratégias do neoextrativismo fomentou o chamado comunitarismo andino-amazônico (Sousa Santos, 2016).

Acentuado estas especificidades é possível compreender como essas prática política dos governos progressistas constituíram uma nova configuração políticoeconômico e social na América Latina.

\subsubsection{Crescimento Econômico, Avanço das Políticas Sociais e o Caso Colombiano.}


O neoextrativismo atingiu níveis de crescimento econômico jamais visto nas economias do sul global. Essa ascendência superou índices de países altamente industrializados e de economias emergentes. A consequência disso foi a liquidação de dívidas externas e alcance de vultuosos superávits fiscais. Na esteira disto houve maior arrecadação tributária o que permitiu ampliar as políticas de contenção da desigualdade social.

Tal êxito econômico permitiu o alcance de avanços significativos na área social, tais como: redução da extrema pobreza e ampliação da classe média (caso boliviano). Diminuição significativa do índice de analfabetismo e de mortalidade infantil (caso venezuelano) ${ }^{11}$. Por fim, há que se falar também dos programas de transferência de renda que no caso equatoriano atingiu um índice de cobertura de $40 \%$ da população. Esses dados demonstram o alcance político-social do neoextrativismo (Gudynas et al, 2016; Santos, 2016).

Não obstante, para além destas estatísticas exitosas há que se perceber sociologicamente que os fundamentos do neoextrativismo estão baseados em ideologias neoliberais, quais sejam: desenvolvimento social fundamentado na ideia de progresso contínuo (Martins, 2017). Dois: emancipação econômica baseada no idealismo de consumo como um modo de vida (Gudynas, 2016). Negação dos impactos sociais e ambientais promovido pela política de exploração de recurso natural dos países periféricos (Svampa, 2016; Martins, 2017).

Assim sendo, observamos que tanto as práticas políticas quanto o investimento nos programas sociais provocaram o desmantelamento dos acordos republicanos na qual o estado perde o poder de guardião dos bens sociais comuns e de protetor dos recursos naturais da nação.

Segundo Svampa (2016), o neoextrativismo abriu uma fase de criminalização e violação dos direitos humanos, pois nos últimos anos aumentaram os conflitos socioambientais e territoriais que envolvem trabalhadores, camponeses, comunidades

\footnotetext{
${ }^{11}$ Vale salientar, sobretudo, para o caso venezuelano, que esses dados foram coletados no período anterior ao ano de 2016. Ou seja, a realidade social da Venezuela naquela época era diferente da situação calamitosa que presenciamos atualmente (abril, 2018).
} 
indígenas e operários urbanos. 0 caso da usina Belo Monte no Brasil e as mobilizações contra a extração de recursos minerais na Argentina são fatos verídicos dessa realidade.

Com efeito, nesta nova fase de exploração dos recursos da nação há que se compreender a relevância das ações estratégicas neoliberais que, por lado, incentiva reprimarização da economia latino-americana e, por outro, defende a flexibilização de entraves para exportação de recursos naturais para os países de economia central isto na prática fortalece a captação de recursos do capital especulativo colonizador (Martins, 2017; Santos, 2016).

O neoextrativismo agiu como um dispositivo preocupado em legitimar o processo de extração de recursos com o mínimo de retribuição social. Isto demonstrou como a política neoliberal representa uma nova faceta dos antigos modos de exploração dos recursos naturais, pois: "como aquele padrão de acumulação baseado na exploração dos recursos naturais, na maioria das vezes, são designados como recursos não renováveis como a expansão das fronteiras territoriais que antes eram vistos como "improdutivos" (Svampa, 2012, p.2, tradução nossa).

Com efeito, a estratégia neoliberal de reorganização do poder estatal estava reajustando os pactos entre as empresas transnacionais e as oligarquias nacionais, gerando ganhos especulativo e financeiro importante que a classe política oligárquica, supostamente, intermediou os tratados de paz a fim de assegurar garantias institucionais das agências regulatórias internacionais para atrair maiores investimentos do capital especulativo na região.

Por isso, ações e acordos de paz coordenada pela classe dirigente oligárquica, hipoteticamente, configurou um dispositivo estratégico para favorecer a ampliação da capacidade produtiva da região o que sociologicamente alguns autores denominaram de paz neoliberal (Sousa Santos, 2017²).

Neste contexto o dispositivo da paz neoliberal levaria à expansão de fronteiras territoriais, emancipação da nação e maior dinamismo liberando mais terra para a exploração multinacional extrativista.

12 Para maiores informações ver: Sousa Santos (2017) em Democracia y transformación social. 
Assim sendo, emergiu a urgência de implementar acordos políticos como os tratados de paz capaz para garantir a estabilidade política e social do país e, consequentemente, estimular o propalado desenvolvimento econômico da nação.

Essa negociação ficou criticamente conhecida como paz ex-press, ou seja, a ideia de paz como um bem comum da nação transforma-se em dispositivo político com objetivo de cumprir os prazos e as condições necessárias para a negociação e ratificação de tratados de livre comercio (TLC) com a União Europeia (EU), por exemplo.

Vale ressaltar que o fato político-simbólico da indicação e ratificação do então presidente J. M. Santos para o prêmio nobel da paz configurou um ato de apoio da oligarquia transnacional à política colombiana que ao promover tratados para assegurar o acordo em prol da paz, na verdade, tal configuração visou criar uma conjuntura política favorável ao estabelecimento de novos acordos comerciais na região (Sousa Santos, 2017).

Por fim, ficou evidente que a proposta de paz neoliberal tendeu a defender a mercantilização da natureza através de mecanismos de controle transnacional e da submissão às agências regulatórias internacionais que gerenciavam atentamente o desenrolar das negociações (Urrea \& Forero, 2016). Em outras palavras, a paz neoliberal, numa perspectiva econômico-social, serviu como garantia para expansão e aprofundamento do regime neoextrativista colombiano.

Diante desta constatação sombria e utilitarista fica uma questão: como interpretar a atuação dos movimentos sociais em prol da paz compreendida como um bem republicano de justiça social?

Para responder a esta questão faz-se necessário compreender como as políticas neoliberais fragmentaram os regimes de esquerda latino-americanos.

\section{O Ressurgimento do Neoliberalismo e a Queda dos Regimes de Esquerda}

A partir da implementação do neodesenvolvimentismo e do neoextrativismo emergiu um cenário de esgotamento da tradição republicana preocupada com a autonomia da nação e com empoderamento ativo do cidadão latino-americano. Em 
consequência disto fragmentou-se a noção do estado como ente republicano reativador de garantia jurídico-social da sociedade politicamente organizada.

Paralelamente, emerge o neoliberalismo numa conjuntura política caracterizada pelo esgotamento do pensamento político plural e pelo enfraquecimento do diálogo com os movimentos sociais o que corroeu a base de sustentação dos governos de esquerda.

A ideia da liberdade como elemento primordial da prática econômico-social foi defendida como a solução para o retorno do protagonismo econômico na América Latina. Para tanto os tecnocratas utilizaram estratégias autoritárias disfarçadas de democráticas, uma vez que o sistema judiciário e o Ministério Público atuam como árbitros na balança de poder em favor das oligarquias burocráticas (Martins, 2017; Sousa Santos, 2017) com isso o neoliberalismo propaga a distopia de um mundo sem política ao defender que a sociedade global possa ser gerenciada apenas pela ordem econômica internacional do livre mercado.

Atrelado a isso o sistema político passou por transformações onde o foco principal foi fragmentar o papel do estado como arquiteto da organização político-moral do bem comum social. Deste modo, o neoliberalismo defendeu que o nacionalismo expresso na utopia política do estado de bem-estar republicano deveria ser substituído por ideologias cosmopolitas que na prática desmantelam a segurança social (Martins, 2017, 2018).

Por isso, há que se perceber que a nova onda neoliberal na América Latina reorganizou o jogo político dos sistemas eleitorais ao se aliar com as oligarquias políticas administrativas e atores políticos tradicionais que se mantém no poder há décadas mobilizando interesse utilitarista que enfraquece o papel republicano organização política da sociedade.

Com isso o neoliberalismo conseguiu um breve período de euforia econômicosocial que amenizou calamidades sociais da região. Em termos "democráticos" ativou-se o protagonismo da antipolítica oligárquica que destravou práticas autoritárias e reprimiu bandeiras utópicas da igualdade ao demarcar o novo triunfo das elites nacionais que se aliaram à empresa especulativa multinacional.

Ainda argumentando sobre a fragilização democrática na perspectiva da política neoliberal é relevante compreender que a balança de poder no pacto político utilitarista 
favoreceu a oligarquia financeira o que gerou descrédito do sistema político, uma vez que foi desfeita a fantasia moral da política neoliberal.

Por isso o pensamento antiulitarista afirmou que prática mercantil do neodesenvolvimentismo e do neoextrativismo foi uma falsa estabilização macroeconômica que atendia ao princípio da lógica neoliberal do sul global.

Isto na prática demonstrou que ambas as políticas neoliberais agravaram os problemas sociais. Por um lado, o poder político-econômico continuou concentrado nas mãos de uma pequena classe econômico-oligárquica dirigente. Por outro, permaneceu elevado o índice de extrema pobreza na região devido à baixa capacidade estatal de redistribuir recursos aos mais necessitados na conjuntura de fragmentação dos bens comuns da crise financeira.

Sobre a verdadeira face das políticas neoliberais latino-americanas é prudente compreender que:

O enfraquecimento do poder estatal é observado pela sua incapacidade de regular administrativamente o jogo de interesse das grandes empresas globais e nacionais como pela crescente dificuldade de manter a governabilidade. Tal enfraquecimento coloca importantes questões sobre novos modos de organização da política de maneira a responder à complexidade do sistema-mundo atual e à importância de uma regulação autorresponsável dos poderes nacionais e locais e das práticas associativas do cotidiano (Martins, 2017, p.5).

Com efeito, o "retorno" da oligarquia político-administrativa, o encolhimento do estado, a reorganização do sistema político a favor das novas elites e o aparecimento do capitalismo cibernético como novo ator social (Martins, 2018) promoveu nova prática de ativismo político preocupado com a reivindicação democrática da pluridiversidade e de ações coletivas que almeja reestabelecer a tradição dos acordos republicanos como um bem da nação.

Diante dessa conjuntura para o sociólogo Boaventura Sousa Santos em: A Difícil Democracia (2016) a queda dos regimes de esquerda no sul global se deu pelo fato das administrações progressistas proporem melhorias sociais "lutando com o capitalismo" (p.174). Para esse pensador é preciso "lutar contra o capitalismo, forjando novas experiências de sociabilidade tais como: o cooperativismo e a reciprocidade" (idem).

Dado essa visão conjuntural sobre o esgotamento da política progressista há que se entender que tal dispositivo foi implementado de maneira unidirecional, ou seja, a 
emergência desta ação econômica utilitarista não derivou de um amplo acordo republicano capaz de dotar o cidadão de autonomia política para melhor usufruir o direito coletivo. Ao contrário, na aliança neoliberal com a oligarquia política o estado centralizou as ações e os cidadãos foram atores passivos neste jogo político.

$\mathrm{Na}$ verdade, as políticas progressistas não conseguiram reverter problemas estruturais da nação como a valorização de projeto político que protagonizasse o empoderamento de reconhecimento social capaz de proporcionar experiência de cidadania ativa.

Ou seja, as políticas neoextrativista e neodesenvolvimentista não desenvolveram alternativas à dependência do capital especulativo global. Pelo contrário, elas tiveram como maior "êxito" transferir recurso oriundo de atividade extrativa para o centro de poder do norte global o que fragilizou a segurança soberana de bens ecológico-político da nação (Gudynas et al, 2016).

\section{Considerações Finais}

A partir desta explanação ficou evidente como a reorganização do poder oligárquico fragmentou os regimes de esquerda que para se adequar à ordem neoliberal encolheu o poder de redistribuição dos bens sociais comuns, colapsou financeiramente e perdeu apoio popular fundamental para defender a importância dos bens sociais latinoamericano.

Ao realizar o exercício interpretativo de compreender a realidade política fragilizada pela ausência de líderes populares e pela escassez de política de reconhecimento social foi necessário descer da superestrutura para tecido social da trama interativa a fim de repensar novas possibilidades reconstrução do sul global.

Para tanto recorremos ao ideal de refundação do igualitarismo moral mobilizados por Sousa Santo (2016) e aos argumentos do republicanismo solidário proposto por Martins (2017) com o intuito de repensar novas possibilidades de ativismo político a partir das ações coletivas. Essas mobilizações foram interpretadas como atores sociais capazes de propor maneiras de ser-pensar-agir preocupada com o projeto 
emancipacionista de desorganização do poder oligárquico instalado na região (Sousa Santos, 2016; Martins, 2017).

Deste modo, foi relevante compreender a importância do ativismo político para preservar dois fundamentos político-morais de empoderamento social. 0 primeiro tem a ver com o compromisso coletivo de reinventar práticas políticas preocupada com a preservação do pensamento de esquerda, visto que: “a esquerda é um conjunto de posições políticas que partilham o ideal de que todos os humanos têm o mesmo valor e são o valor mais alto" (Sousa Santos, 2016, p. 173).

0 segundo fundamento a ser preservado diz respeito à necessidade das ações coletivas fortalecerem a luta pela preservação da tradição republicana como fundamento para a organização política da sociedade, uma vez que: "O republicanismo constitui um pacto de poder visando organizar uma linguagem política coletiva articulando diferenças de interesses que remetem aos tempos antigos" (Martins, 2017, p. 8).

Por fim, é prudente reconhecer que no atual momento de desorganização dos pactos republicanos é fundamental repensar a ressignificação das lutas sociais como utopias geradoras de sentido capaz de transformar o "desencanto do mundo" (Weber, 1999) e dar significado aos laços de solidariedades e as pluralidades de ação desprovida do interesse mercantil para que as ações coletivas latino-americanas possam contribuir no processo de restabelecimento da utopia republicana como um bem comum solidário da nação.

\section{Referências}

ALVES, G., (02 de dezembro de 2013), Neodesenvolvimentismo e Estado neoliberal no Brasil. Blog da Boitempo [Blog]. Recuperado de https://blogdaboitempo.com.br/2013/12/02/neodesenvolvimentismo-e-estadoneoliberal-no-brasil/

ALVES, G., (27 de novembro de 2014), 0 mal-estar do neodesenvolvimentismo. Blog da Boitempo [Blog]. Recuperado de https://blogdaboitempo.com.br/2014/11/27/o-malestar-do-neodesenvolvimentismo/

ARENDT, H., (2008), Homens em tempos sombrios. Editora Companhia das Letras. 
Pleyers, G., \& Bringel, B. (2017). Protestas e indignacón global. Movimientos sociales en el nuevo orden mundial. Ediciones Clacso, 2017.

BAUMAN, Z., (1998), O mal-estar da modernidade. Rio de Janeiro: Jorge Zahar, 122.

BOITO JR, A. \& BERRINGER, T. (2013) Brasil: classes sociais, neodesenvolvimentismo e política externa nos governos Lula e Dilma. Revista de Sociologia e Política, v. 21, n. 47.

CAILlÉ, A., (2013), o Dom entre interesse e "desinteressamento". Revista de Estudos Antiutilitaristas e Pós-Coloniais. v. 3, n. 1, p. 7-42.

CUSSET, F. (agosto 3 de 2017) Em Chiapas, a revolução continua. Le Monde Diplomatique. Recuperado de https://diplomatique.org.br/em-chiapas-a-revolucaocontinua/

DARDOT, P. \& LAVAL, C., (2016), A nova razão do mundo: ensaios sobre a sociedade neoliberal. São Paulo, SP: Editora Boitempo.

GOHN, M., (2017), Manifestações e protestos no Brasil: Correntes e contracorrentes na autalidade. São Paulo: Cortez.

GIDDENS, A., (2001), A terceira via e seus críticos. Rio de Janeiro: Record

GUDYNAS, E. et al. (2016). Los progresismos sudamericanos: Ideas y prácticas, avances y límites. Rescatar la esperanza. Más alla del liberalismo y el progressismo. Barcelona: Ed. Entrepueblos.

HONNETH, A., (2015), O direito da liberdade. Martins Editora.

LOZANO GUILLÉN, (2014), El nuevo país está en marcha. 1 ed. Bogotá: Ocean Sur.

MARTINS et al. (2014), Modelos Alternativos de Desenvolvimento. In: Martins et al. (Org.). Guía sobre post-desarrollo y nuevos horizontes utópicos. Ciudad Autónoma de Buenos Aires: Estudios Sociológicos Editora.

MARTINS, P.H., (2016), Democracia, pós-desenvolvimento e gestão de bens comuns: perspectivas da América Latina e do Caribe. SP: Annablume

MARTINS, P.H., (2017), Republicanismo solidário e missão da universidade pública. In: Conferência realizada na UFPE sob iniciativa do Reitor Anísio Brasileiro dentro das atividades preparatórias da participação da UFPE na III Conferência Regional de Educação Superior da América Latina e Caribe a ser realizada no ano de 2018 na cidade de Córdoba, Argentina.

MARTINS, P.H., (2018), Crítica sociológica al poder oligárquico en América Latina (No prelo)

MATTEI, L., (2013), Gênese e agenda do novo desenvolvimentismo brasileiro. Revista de economia política, v. 33, n. 1, p. 130. 
SADER, E., (org.) (2013). 10 anos de governos pós-neoliberais no Brasil: Lula e Dilma. São Paulo, SP: Boitempo; Rio de Janeiro: FLACSO Brasil.

SADER, E., (2010) A nova toupeira. Os caminhos da esquerda latino-americana. São Paulo: Boitempo.

SANTOS, W. G., (2017), A democracia impedida: o Brasil no século XXI. RJ: FGV Editora. SOUZA, J. (2017). A elite do atraso: da escravidão à Lava Jato. RJ: Leya.

SOUSA SANTOS, B. (2016). A difícil democracia: reinventar as esquerdas. SP: Boitempo.

SOUSA SANTOS, B., (2017). Democracia y transformación social. Bogotá: Siglo del hombre editores, Siglo XXI editores.

SVAMPA, M., (2012) Consenso de los commodities, giro ecoterritorial y pensamiento crítico en América Latina. Osal, v. 13, n. 32, p. 15-38.

SVAMPA, M., (2016), América Latina: Fin de ciclo y populismos de alta intensidad. In Gudynas et al., (2016), Rescatar la esperanza. Más alla del liberalismo y el progressismo. Barcelona: Ed. Entrepueblos.

URREA, D. \& FORERO, L., (28 de setembro de 2016), Paz territorial y acaparamiento en Colombia. Transnational Institute [Blog]. Recuperado de https://www.tni.org/es/art\%C3\%ADculo/paz-territorial-y-acaparamiento-en-colombia

WEBER, M., (1999). Economia e sociedade: fundamentos da sociologia compreensiva. v. 1. Brasília: UnB, 209-227. 